\title{
Diagnosis and Care of Chronic Health Conditions Among Medicaid Expansion Enrollees: a Mixed-Methods Observational Study
}

\author{
Ann-Marie Rosland, $M D, M S^{1,2}$, Edith C. Kieffer, $P h D, M P H^{3,4}$, \\ Renuka Tipirneni, MD, MSc ${ }^{4,5}$, Jeffrey T. Kullgren, $M D, M S, M P H^{4,5,6}$, Matthias Kirch, $M S^{4}$, \\ Emily K. Arntson, MS', Sarah J. Clark, MPH ${ }^{4,8}$, Sunghee Lee, $P h D^{4,9}$, \\ Erica Solway, PhD, MSW, MPH', Erin Beathard, MSW, MPH', \\ John Z. Ayanian, MD, MPP4,5,7,10, and Susan D. Goold, MD, MHSA, MA $4,5,7$
}

'Department of Medicine, University of Pittsburgh School of Medicine, Pittsburgh, PA, USA; ${ }^{2}$ VA Pittsburgh Center for Health Equity Research and Promotion, Pittsburgh, PA, USA; ${ }^{3}$ University of Michigan School of Social Work, Ann Arbor, MI, USA; ${ }^{4}$ Institute for Healthcare Policy and Innovation (IHPI), University of Michigan, Ann Arbor, MI, USA; ${ }^{5}$ Division of General Medicine, University of Michigan School of Medicine, Ann Arbor, MI, USA; ${ }^{6} \mathrm{VA}$ Ann Arbor Center for Clinical Management Research, Ann Arbor, MI, USA; ${ }^{7}$ Department of Health Management and Policy, University of Michigan School of Public Health, Ann Arbor, MI, USA; ${ }^{8}$ Child Health Evaluation and Research Center, University of Michigan, Ann Arbor, MI, USA; Institute for Social Research, University of Michigan, Ann Arbor, MI, USA; ${ }^{10}$ Gerald R. Ford School of Public Policy, University of Michigan, Ann Arbor, MI, USA.

BACKGROUND: It is uncertain how Medicaid expansion under the Affordable Care Act influences the diagnosis of chronic health conditions, and the care and health of enrollees with chronic conditions.

OBJECTIVE: Describe the prevalence of new and preexisting chronic health conditions among Medicaid expansion enrollees. Examine whether perceived changes in specific types of access and self-rated health status differed between enrollees with chronic conditions and those without. Examine how gaining Medicaid coverage affected chronic disease management and well-being.

DESIGN: Mixed-methods study including a telephone survey and semi-structured interviews.

SETTING: Michigan's Medicaid expansion, the "Healthy Michigan Plan" (HMP).

PARTICIPANTS: 4090 survey respondents (response rate $54 \%$ ) with $\geq 12$ months HMP enrollment and 67 interviewees with $\geq 6$ months enrollment.

MAIN MEASURES: Self-reported chronic condition diagnoses, changes in physical/mental health, and healthcare access. Descriptive survey data were adjusted for survey design and nonresponse. Semi-structured interview questions about how gaining HMP coverage led to changes in health status.

KEY RESULTS: Among enrollees, $68 \%$ had a selfreported diagnosis of a chronic health condition; $42 \%$ of those were newly diagnosed since HMP enrollment. In multivariable models, enrollees with chronic conditions were significantly more likely to report improved physical (adjusted odds ratio (aOR) 1.70, 95\% CI $(1.40,2.07))$ and

This paper was presented at the Society of General Internal Medicine and Academy Health Annual Research Conferences in 2017.

Electronic supplementary material The online version of this article (https://doi.org/10.1007/s11606-019-05323-w) contains supplementary material, which is available to authorized users.

Received January 3, 2019

Revised May 15, 2019

Accepted August 13, 2019

Published online September 11, 2019 mental health (aOR 1.75, (1.43, 2.15)) since HMP enrollment than enrollees without chronic conditions. Among enrollees with chronic conditions, the strongest predictors of improvements in health were having seen a primary care physician, improved mental health care access, and improved medication access. Interviewees with chronic conditions described how increased access to health care led to improvements in both physical and mental health.

CONCLUSIONS: Enrollees with expanded Medicaid coverage commonly reported detection of previously undiagnosed chronic conditions. Perceived health status and access improved more often among enrollees with chronic health conditions. Improved access was associated with improved physical and mental health among this vulnerable group.

J Gen Intern Med 34(11):2549-58

DOI: $10.1007 / \mathrm{s} 11606-019-05323-\mathrm{w}$

(c) Society of General Internal Medicine 2019

\section{INTRODUCTION}

Over half of US adults have a chronic health condition and have increased risk for poor health outcomes. ${ }^{1,2}$ The prevalence of chronic conditions is increasing over time, ${ }^{3}$ and chronic health conditions are more prevalent in lower income areas than in more affluent ones. ${ }^{4}$ Expanded eligibility for Medicaid under the Affordable Care Act (ACA) may enable earlier diagnosis of chronic health conditions, and access to affordable health care for low-income adults with chronic conditions, ${ }^{5}$ providing opportunities to prevent disabling symptoms and complications from these health conditions.

For those with chronic conditions, gaining access to care has clearly been linked to better control of chronic conditions, and better overall health. ${ }^{5-10}$ Michigan is one of 36 states that have expanded access to their Medicaid programs under the 
ACA. Michigan received a Section 1115 demonstration waiver to implement the Healthy Michigan Plan (HMP), ${ }^{11}$ which currently covers approximately 670,000 lower income adults. Michigan's HMP has a cost-sharing structure that includes copays for enrollees at most income levels and premium-like contributions for those with incomes above $100 \%$ of the federal poverty level. HMP also has unique features that could benefit those with chronic health conditions including waiving copays for services and medications related to numerous chronic conditions, incentives for early engagement with primary care, and financial incentives for completing a health risk assessment and choosing health goals such as smoking cessation or weight loss. ${ }^{11}$

While past studies have shown improvements in access ${ }^{12,13}$ and overall self-rated health status ${ }^{12-14}$ among those acquiring Medicaid coverage, little is known about whether Medicaid coverage is particularly linked to improving physical and mental health status for people with chronic health conditions, and whether improved access to specific types of care may be particularly important to improving health for those with chronic conditions. In addition, identifying the number and characteristics of Medicaid expansion enrollees with chronic health conditions can help programs anticipate enrollee needs. People with chronic conditions have a greater need for health care services and may be more likely to have "pent-up demand" ${ }^{, 5,15,16}$ if care needs were not adequately met previously. The prevalence of chronic health conditions among Medicaid expansion enrollees may differ from traditional Medicaid enrollees, as adults who enroll via Medicaid expansion are older, more likely to be men, ${ }^{17}$ and less likely to be enrolling due to disability status. ${ }^{18}$

This study evaluated the following four domains: (1) the prevalence of existing and new diagnoses of chronic health conditions among all HMP enrollees, (2) whether perceived access to key types of care changed more for those with chronic conditions compared with those without, (3) whether improvements in self-rated physical and mental health status were more common among those with chronic conditions than those without, and (4) how gaining HMP coverage may have resulted in new diagnoses, improved ability to treat and manage disease, and improved well-being.

\section{METHODS}

\section{Study Design}

Data were obtained from a mixed-methods observational study of HMP enrollees during the first 2 years of HMP, conducted as part of a demonstration evaluation funded by the Michigan Department of Health and Human Services (MDHHS). As a federally mandated evaluation of a government health program, this study was classified as exempt from review by the Institutional Review Boards of the University of Michigan and MDHHS.
Our overall approach to this study was guided by the Chronic Care Model, ${ }^{19}$ which highlights the importance of detection and population management of chronic conditions, multimodal treatment of chronic conditions, links to community resources such as healthy lifestyle programs, and attention to both physical and mental health in supporting selfmanagement of chronic conditions.

Survey Cohort. A telephone survey was conducted between January and October 2016. Current HMP enrollees were randomly sampled in strata chosen to ensure representation of enrollees by income (0-35\%, 36-99\%, and 100-138\% of the federal poverty level [FPL]) and four geographic regions of the state. Inclusion criteria were as follows: age 19-64; $\geq$ 12 months total HMP enrollment with $\geq 9$ months in an HMP managed care plan; and preferred language English, Spanish, or Arabic. Of 9227 enrollees selected, 4090 completed the survey (representing a weighted cohort of 379,627 enrollees). The weighted response rate was $53.7 \%$, using the American Association for Public Opinion Research formula. ${ }^{20}$ Additional details on survey design, response rate, and non-respondents are located in Online Appendix Tables 3 and 4.

Survey Measures. The presence of chronic disease diagnoses was measured by asking, "Has a doctor or other health professional ever told you that you had any of the following: Hypertension, also called high blood pressure; a heart condition or heart disease; diabetes or sugar diabetes (other than during pregnancy); a stroke; asthma; chronic bronchitis, COPD, or emphysema; a mood disorder, for example depression, anxiety or bipolar disorder?" This wording is similar to that used in other national surveys such as the Behavioral Risk Factor Survey (BRFS) and National Health Interview Survey (NHIS). ${ }^{21,} 22$ The survey also asked about diagnosis of "Any other ongoing health condition that can be controlled but not cured." Responses to this open-ended item were coded as consistent or not with a chronic health condition by two clinicians, and disagreements were resolved by consensus. The most common "other" chronic diagnosis categories were chronic joint or back pain, thyroid conditions, and hyperlipidemia. For each chronic condition reported, we asked, "Did you find out you had [condition] before or after you enrolled in the Healthy Michigan Plan?"

Respondents were asked whether their physical or mental health status had improved, using this item: "Overall, since you enrolled in the Healthy Michigan Plan, would you say your [physical health/mental health] has gotten better, stayed the same, or gotten worse?" We chose this question to assess perceived health status changes because significant differences were detected by this question between enrollees in the Oregon Medicaid program and similar non-enrollees. ${ }^{14}$

Items adapted from the NHIS assessed access to and utilization of health services. Perceived changes in access to services were assessed using the question, "Would you say that your ability to get [care type] through the Healthy Michigan Plan is better, worse or about the same, compared to 
before?"; care types included "primary care," "specialist care," "mental health care," and "prescription medications." Wording for items assessing regular source of care, primary care provider (PCP) visits, ability to pay medical bills, and functional impairment can be found in Online Appendix Table 5. Standard measures assessed demographics, health status, and insurance status. ${ }^{21,23-26}$

Michigan Behavioral Risk Factor Survey Data. To provide a descriptive comparison of prevalence of conditions in HMP to that of a similar Michigan population, we obtained data for 5939 respondents to the 2015 Michigan BRFS population survey who would meet selected HMP eligibility criteria (19-64 years old, not pregnant, and not eligible for Medicare as a proxy for disability status in this age group) (see Online Appendix Table 5 for wording of Michigan Behavioral Risk Factor Survey (MiBRFS) questions used). Among the included MiBRFS respondents, $14 \%$ had household income at $100 \%$ FPL or less, and another 7\% at 100-138\% FPL. Most (92\%) had health insurance coverage in the year prior to the survey. It is possible that some MiBRFS respondents in this income range were enrolled in HMP. While the MiBRFS group does not serve as a "control group," it does benchmark the prevalence of chronic conditions among low-income Michigan residents to lend context to our analyses.

Statistical Analysis. Survey responses were weighted to adjust for sample design and nonresponse, yielding proportions that were representative of the HMP enrollee population meeting the survey eligibility criteria. We first assessed weighted chronic health condition prevalence and self-reported new diagnoses among HMP enrollees. These findings were compared with data on chronic disease prevalence from included MiBRFS respondents that was adjusted for MiBRFS survey sampling weights, then standardized to the HMP enrollee age and sex distribution. We then compared HMP enrollee characteristics and self-reported health status and utilization among those with and without a chronic health condition. Multivariable logistic regression models assessed the association between having a self-reported chronic condition and perceived changes in physical and mental health since HMP enrollment. Among enrollees with a chronic health condition, a second multivariable logistic regression model assessed independent associations between self-reported improvements in access to primary care, specialty care, mental health care, and prescriptions with reported changes in physical and mental health status since HMP enrollment. Both models were adjusted for insurance status prior to HMP, age, sex, income, and race/ethnicity, and smoking status. Variables measuring perceived changes in access to various types of care (e.g., prescription medications, mental health care, specialty care) were not significantly correlated with each other. Analyses were performed with Stata version 14.2, and two-tailed $p$ values $<.05$ were considered statistically significant.
Qualitative Interviews and Analysis. In-depth, semistructured interviews were conducted with 67 HMP enrollees from five Michigan regions between April and August 2015 to inform general development of the enrollee surveys and to add further evidence and context to telephone survey results. Enrollees with $\geq 6$ months HMP enrollment who had used an HMP-covered health care service were eligible for inclusion. Purposive sampling methods were used to select a diverse group of interviewees in regard to gender, age, race/ethnicity, income, and urban/rural residence (Online Appendix Table 1). The interview assessed topical domains through open-ended questions with follow-up probes. Interview questions explored the types of health services enrollees had used after HMP enrollment, including preventive and specialty care, prescriptions, and medical equipment and supplies, and changes in self-care for health conditions and in health status since enrolling in the program (Online Appendix Table 2). Interviews were audio recorded, transcribed verbatim, and coded iteratively using in-depth coding and thematic analysis, ${ }^{27,}{ }^{28}$ with the aid of Dedoose software (http://www. dedoose.com). For this study, emergent themes were further analyzed in the context of the Chronic Care Model and study aims, to elucidate information on the influence of HMP coverage on diagnosis of previously symptomatic and asymptomatic chronic conditions, how perceived physical and mental health changed among those with chronic conditions, and how enrollees with chronic conditions perceived links between obtaining access to health care and changes in their health status.

\section{RESULTS}

\section{Prevalence of Previously Diagnosed and Newly Diagnosed Chronic Health Conditions}

Two-thirds (68\%) of HMP enrollees reported having a chronic health condition. The most common chronic conditions reported were hypertension ( $31 \%$ of enrollees), mood disorders $(30 \%)$, and asthma (17\%) (Fig. 1). Forty-two percent of enrollees with a chronic health condition ( $30 \%$ of all enrollees) reported that at least one of their chronic conditions was newly diagnosed since HMP enrollment. The most frequent chronic condition diagnosed since HMP enrollment was chronic lung disease (36\% of all those with this condition). Similar proportions (29-35\%) of those with hypertension, mood disorders, diabetes, and heart disease reported being newly diagnosed. New diagnoses of asthma accounted for only $13 \%$ of all those with asthma. MiBRFS data matched to the age/sex distribution of HMP enrollees showed that the self-reported prevalence of each chronic condition assessed was lower in this more general Michigan population than among HMP enrollees (Fig. 1). The smallest absolute difference was found for diabetes (7\% of similar Michigan population vs. 11\% of HMP enrollees). The other chronic conditions were found in an additional 5- 


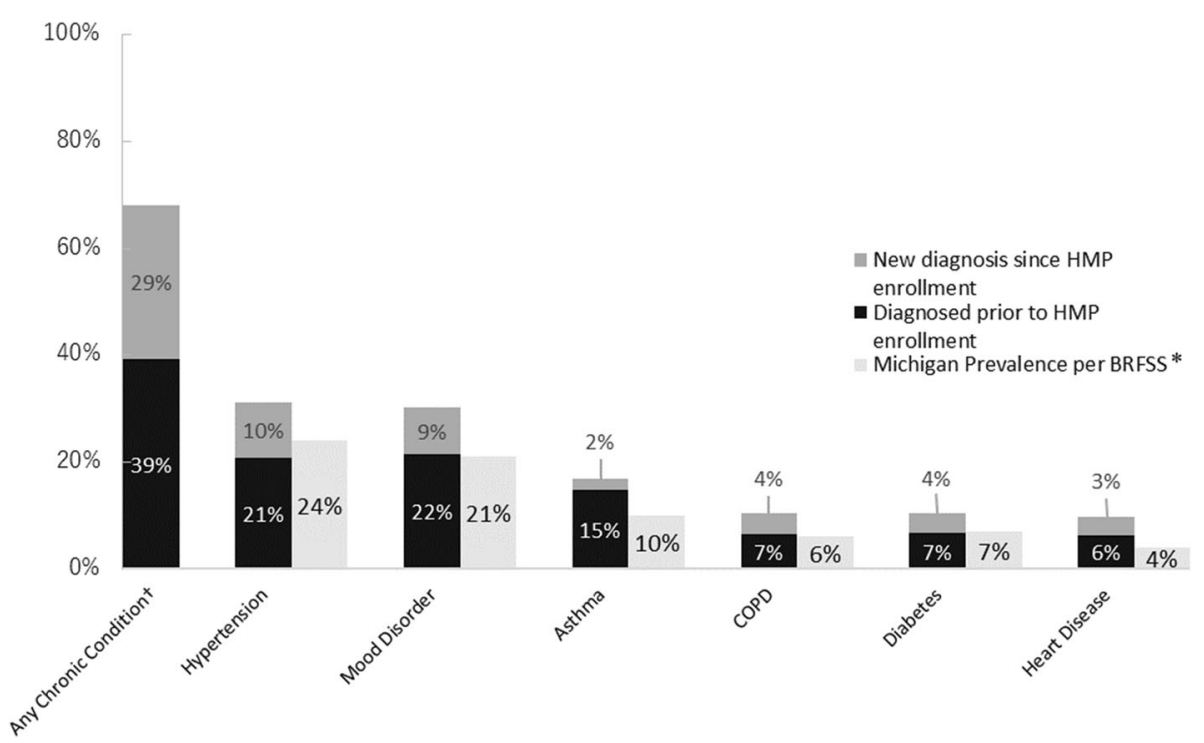

Figure 1 Prevalence of chronic conditions—-previously vs. newly diagnosed since Healthy Michigan Plan enrollment. COPD, chronic obstructive pulmonary disease. *Comparable Michigan Prevalence* estimated using 2015 Michigan BRFSS results among respondents age 19-64 years old who did not report being pregnant or enrolled in Medicare, adjusted for BRFSS survey weights to more closely reflect the general Michigan population. ${ }^{\dagger}$ Any chronic condition includes respondents who reported any of the following conditions: hypertension, heart disease, diabetes, mood disorders, stroke, asthma, COPD, or other. Write-in responses for "other" were verified and coded by two clinicians. Of all respondents with any chronic disease, $39.4 \%$ reported some "other" chronic disease, but only $8.9 \%$ of those with a chronic disease only selected "other." Among all enrollees, a total of 6657 chronic diseases were indicated, including 1538 classified as "other" (23\% of reported chronic conditions).

$10 \%$ of the HMP enrollee population compared to the similar Michigan population.

\section{Characteristics of Enrollees With or Without Chronic Health Conditions}

Compared with those without chronic health conditions, enrollees with chronic health conditions were more likely to be White and have an income of $0-35 \%$ FPL (Table 1). While those with chronic conditions were more likely than those without to fall in the older (51-64 years old) age range $(31 \%$ vs. $16 \%)$, a third of those with chronic health conditions were 19-34 years old. Most $(58 \%)$ of those with a chronic condition reported two or more concurrent chronic diagnoses; $12 \%$ had four or more. Enrollees with chronic health conditions were more likely than those without (24\% vs. $6 \%$ ) to report significant functional limitations in daily life. Those with chronic conditions were much more likely than those without to report current poor or fair health status $(39 \%$ vs. $10 \%)$.

Enrollees with chronic conditions were more likely to report having problems paying medical bills in the 12 months prior to HMP enrollment than those without chronic conditions (52\% vs. $30 \%, p<.001)$ although both groups were similarly likely to have had health insurance during that time ( $40 \%$ vs. $41 \%$ had coverage for all or part of the year; Table 2). However, those with chronic conditions were more likely than those without chronic conditions to report having had a usual source of care (including ED, urgent care, clinic, or doctor's office; $77 \%$ vs. $67 \%, p<.001)$, and having seen a PCP (43\% vs. $37 \%$, $p=.02$ ) during the year prior to enrollment.

\section{Changes in Access to and Sources of Care}

Enrollees with chronic conditions were more likely than those without to report a usual source of care over the previous 12 months since enrolling in HMP (95\% vs. $86 \%, p<.001)$ and also more frequently reported seeing a PCP in the preceding 12 months $(90 \%$ vs. $76 \%$, $p<.001)$. Among enrollees with any chronic health condition, those reporting a new diagnosis of a chronic condition since enrolling in HMP were more likely to have been without health insurance for all 12 months before enrollment $(66 \%$ vs. $56 \%, p<.001)$. Since HMP enrollment, enrollees with chronic conditions were significantly more likely than those without chronic conditions to report improved access to prescription medications (65\% vs. $48 \%)$, specialty care $(50 \%$ vs. $33 \%)$, and mental health care $(32 \%$ vs. $17 \%)($ all $p<.001)$.

\section{Changes in Health Since HMP Enrollment}

When asked about their health since HMP enrollment, those with chronic health conditions were more likely to report improved physical health (52\% vs. $40 \%)$ and improved mental health (43\% vs. $29 \%$ ) compared with those without chronic conditions. In multivariable logistic regression models adjusted for other factors likely to affect health status (Table 3), enrollees with chronic health conditions were significantly more likely to report improved physical (adjusted odds ratio [aOR] 1.70, 95\% CI (1.40, 2.07)) and mental health (aOR $1.75,95 \%$ CI $(1.43,2.15))$ since HMP enrollment than enrollees without chronic health conditions. 
Table 1 Enrollee Characteristics by Chronic Health Condition Status $(N=4090)$ (Proportions of Enrollee Population Derived from Enrollee Survey Responses Adjusted for Survey Sample Weights)

\begin{tabular}{|c|c|c|c|c|c|}
\hline & \multicolumn{2}{|c|}{$\begin{array}{l}\text { Enrollees without a chronic } \\
\text { condition }(n=1151)\end{array}$} & \multicolumn{2}{|c|}{$\begin{array}{l}\text { Enrollees with any chronic } \\
\text { condition* }(n=2939)\end{array}$} & \multirow[t]{2}{*}{$p$ value } \\
\hline & $\%$ or mean & $95 \% \mathrm{CI}$ & $\%$ or mean & $95 \% \mathrm{CI}$ & \\
\hline \multicolumn{5}{|l|}{ Age, years } & \multirow[t]{4}{*}{$<.001$} \\
\hline $19-34$ & $55.9 \%$ & {$[52.3,59.6]$} & $32.5 \% *$ & {$[30.3,34.8]$} & \\
\hline $35-50$ & $28.2 \%$ & {$[25.0,31.5]$} & $36.7 \% *$ & {$[34.5,39.0]$} & \\
\hline $51-64$ & $15.9 \%$ & {$[13.8,18.3]$} & $30.8 \% *$ & {$[28.9,32.8]$} & \\
\hline \multicolumn{5}{|l|}{ Gender } & \multirow[t]{3}{*}{.015} \\
\hline Female & $47.9 \%$ & {$[44.2,51.5]$} & $53.3 \%$ & {$[51.0,55.6]$} & \\
\hline Male & $52.1 \%$ & {$[48.5,55.8]$} & $46.7 \%$ & {$[44.4,49.0]$} & \\
\hline \multicolumn{5}{|l|}{ Race/ethnicity } & \multirow[t]{5}{*}{$<.001$} \\
\hline White & $54.2 \%$ & {$[50.4,57.9]$} & $64.4 \% *$ & {$[62.2,66.6]$} & \\
\hline Black or African American & $28.8 \%$ & {$[25.3,32.5]$} & $24.8 \%$ & {$[22.8,26.9]$} & \\
\hline Other & $13.1 \%$ & {$[10.8,15.8]$} & $6.8 \% *$ & {$[5.7,8.0]$} & \\
\hline More than one & $4.0 \%$ & {$[2.8,5.6]$} & $4.0 \%$ & {$[3.1,5.1]$} & \\
\hline \multicolumn{5}{|l|}{ Income, $\%$ of federal poverty level } & \multirow[t]{4}{*}{$<.001$} \\
\hline $0-35 \%$ & $45.9 \%$ & {$[42.6,49.4]$} & $54.6 \% *$ & {$[53.1,56.1]$} & \\
\hline $36-99 \%$ & $31.0 \%$ & {$[28.3,33.8]$} & $27.2 \%$ & {$[25.9,28.5]$} & \\
\hline$>100 \%$ & $23.1 \%$ & {$[20.8,25.4]$} & $18.2 \% *$ & {$[17.2,19.3$} & \\
\hline \multicolumn{5}{|l|}{ Number of self-reported chronic conditions } & \multirow[t]{8}{*}{$<.001$} \\
\hline 1 & N/A & & $41.6 \%$ & {$[39.3,43.9]$} & \\
\hline 2 & & & $30.2 \%$ & {$[28.1,32.4]$} & \\
\hline 3 & & & $16.7 \%$ & {$[15.1,18.5]$} & \\
\hline$\geq 4$ & & & $11.5 \%$ & {$[10.2,12.9]$} & \\
\hline No. of last 30 days physical health not good & 3.0 days & {$[2.4,3.5]$} & 8.6 days* & {$[8.1,9.1]$} & \\
\hline No. of last 30 days mental health not good & 2.1 days & {$[1.6,2.6]$} & 7.8 days* & {$[7.3,8.3]$} & \\
\hline \multirow{2}{*}{\multicolumn{5}{|c|}{ Self-rated health status }} & \\
\hline & & & & & \multirow{6}{*}{$<.001$} \\
\hline Excellent & $20.2 \%$ & {$[17.3,23.3]$} & $4.5 \% *$ & {$[3.7,5.6]$} & \\
\hline Very good & $42.5 \%$ & {$[38.8,46.2]$} & $19.5 \% *$ & {$[17.6,21.5]$} & \\
\hline Good & $27.0 \%$ & {$[23.9,30.3]$} & $37.1 \%$ & {$[34.9,39.4]$} & \\
\hline Fair & $9.2 \%$ & {$[7.3,11.7]$} & $28.3 \% *$ & {$[26.3,30.4]$} & \\
\hline Poor & $1.1 \%$ & {$[0.6,2.1]$} & $10.5 \% *$ & {$[9.2,12.0]$} & \\
\hline \multicolumn{5}{|l|}{ Physical health better since HMP enrollment } & \multirow[t]{4}{*}{$<.001$} \\
\hline Gotten better & $39.5 \%$ & {$[35.9,43.2]$} & $52.1 \% *$ & {$[49.7,54.4]$} & \\
\hline Stayed the same & $59.2 \%$ & {$[55.4,62.8]$} & $40.4 \% *$ & {$[38.2,42.7]$} & \\
\hline Gotten worse & $1.4 \%$ & {$[0.8,2.4]$} & $7.5 \% *$ & {$[6.5,8.7]$} & \\
\hline \multicolumn{5}{|l|}{ Mental health better since HMP enrollment } & \multirow[t]{4}{*}{$<.001$} \\
\hline Gotten better & $29.2 \%$ & {$[25.8,32.8]$} & $42.6 \% *$ & {$[40.3,44.9]$} & \\
\hline Stayed the same & $69.6 \%$ & {$[66.0,72.9]$} & $51.2 \%$ & {$[48.9,53.5]$} & \\
\hline Gotten worse & $1.3 \%$ & {$[0.7,2.2]$} & $6.2 \% *$ & {$[5.1,7.4]$} & \\
\hline
\end{tabular}

*Statistically significant difference at $p<.05$ for comparison of enrollees with $v$ s. without a chronic condition

${ }^{\sharp}$ Chronic conditions are self-reported and include hypertension, mood disorders (e.g., depression or anxiety), asthma, heart disease, chronic obstructive pulmonary disease (COPD), diabetes, and chronic health conditions among those listed by respondents as "other" diagnoses

${ }^{s}$ More than 16 days in the last 30 days (CDC definition)

${ }^{\dagger}$ Pearson's chi-squared test

\section{Associations between Changes in Access to Care and Changes in Health Status, Among Enrollees With Chronic Health Conditions}

Among enrollees with chronic health conditions, when adjusted for other factors that can affect health status, seeing a PCP (aOR 1.86, 95\% CI $(1.20,2.89))$ and having improved access to prescription medications (aOR $2.10,95 \% \mathrm{CI}(1.65,2.68)$ ) in the past 12 months of HMP enrollment were the strongest predictors of improved physical health since HMP enrollment (Table 4). Other significant predictors of improved physical health were improved access to specialty care (aOR 1.63, 95\% CI $(1.39,2.05))$ and improved access to mental health care (aOR $1.53,95 \%$ CI $(1.19,1.96))$.

Among enrollees with chronic health conditions, the strongest predictor of improved mental health in adjusted analyses was improved access to mental health care (aOR 3.40, 95\% CI
$(2.67,4.34))$. Other significant predictors were improved access to prescription medications (aOR 1.56, 95\% CI (1.21, $2.02)$ ) and improved access to specialty care (aOR $1.48,95 \%$ CI $(1.17,1.88)$ ), but not whether the enrollee saw a PCP in the past 12 months of HMP enrollment.

\section{HMP Enrollee Interview Themes Related to Chronic Disease Care}

During in-depth interviews, enrollees with chronic conditions described how HMP coverage led to the identification of and treatment for new diagnoses; improved access to needed health care, medications, and supplies for previously diagnosed conditions that improved their functioning and health; and reduced financial stress (see Online Appendix Table 6 for additional HMP enrollee quotations exemplifying the themes described below). 
Table 2 Self-reported Insurance Coverage and Access to Care Before and After HMP Enrollment, by Chronic Health Condition Status

\begin{tabular}{|c|c|c|c|c|c|}
\hline & \multicolumn{2}{|c|}{$\begin{array}{l}\text { Respondents without a } \\
\text { chronic condition }\end{array}$} & \multicolumn{2}{|c|}{$\begin{array}{l}\text { Respondents with any } \\
\text { chronic condition* }\end{array}$} & \multirow[t]{2}{*}{$p$} \\
\hline & $\begin{array}{l}\text { Column } \\
\%\end{array}$ & $95 \% \mathrm{CI}$ & $\begin{array}{l}\text { Column } \\
\%\end{array}$ & $95 \% \mathrm{CI}$ & \\
\hline Insurance duration prior to HMP & & & & & .24 \\
\hline Entire year & 30.0 & $\begin{array}{l}{[26.8} \\
33.5]\end{array}$ & 31.3 & $\begin{array}{l}{[29.2} \\
33.6]\end{array}$ & \\
\hline Part of year & 11.0 & {$[8.8,13.7]$} & 8.8 & {$[7.6,10.2]$} & \\
\hline None of year & 59.0 & $\begin{array}{l}{[55.2} \\
62.6]\end{array}$ & 59.6 & $\begin{array}{l}{[57.5} \\
62.1]\end{array}$ & \\
\hline Years since last PCP visit prior to HMP & & & & & .02 \\
\hline Less than 1 year & 36.7 & $\begin{array}{l}{[33.1} \\
40.4]\end{array}$ & 42.6 & $\begin{array}{l}{[40.4} \\
45.0]\end{array}$ & \\
\hline $1-5$ years & 42.1 & $\begin{array}{l}{[38.4} \\
45.8]\end{array}$ & 36.6 & $\begin{array}{l}{[34.5} \\
38.9]\end{array}$ & \\
\hline More than 5 years & 21.3 & $\begin{array}{l}{[18.5} \\
24.3]\end{array}$ & 20.7 & 22.8] & \\
\hline Saw PCP in past 12 months & 75.5 & 78.8] & 89.8 & $\begin{array}{l}{[88.0} \\
91.3]\end{array}$ & $<.001$ \\
\hline Problems paying medical bills in 12 months prior to HMP enrollment & 29.7 & $\begin{array}{l}{[26.5} \\
33.2]\end{array}$ & 51.9 & $\begin{array}{l}{[49.6} \\
54.2]\end{array}$ & $<.001$ \\
\hline Ability to pay medical bills improved after HMP & 85.4 & $\begin{array}{l}{[79.8} \\
89.6]\end{array}$ & 87.0 & $\begin{array}{l}{[84.6} \\
89.1]\end{array}$ & .048 \\
\hline $\begin{array}{l}\text { Access to prescriptions since HMP enrollment } \\
\text { Improved }\end{array}$ & 48.0 & $\begin{array}{l}{[44.3,} \\
51.71\end{array}$ & 64.6 & $\begin{array}{l}{[62.3,} \\
66.8]\end{array}$ & $<.001$ \\
\hline Same & 28.8 & 325.4 & 24.6 & $\begin{array}{l}{[22.6} \\
26.6]\end{array}$ & \\
\hline Worse & 1.5 & {$[0.9,2.6]$} & 3.9 & {$[3.0,4.9]$} & \\
\hline Do not know & 21.7 & $\begin{array}{l}{[18.9} \\
24.8]\end{array}$ & 7.0 & {$[5.9,8.3]$} & \\
\hline $\begin{array}{l}\text { Access to specialty care since HMP enrollment } \\
\text { Improved }\end{array}$ & 33.0 & $\begin{array}{l}{[29.8} \\
36.5]\end{array}$ & 49.7 & $\begin{array}{l}{[47.4,} \\
52.0]\end{array}$ & $<.001$ \\
\hline Same & 24.9 & 28.3] & 21.5 & [19.7, & \\
\hline Worse & 3.1 & {$[2.1,4.5]$} & 4.8 & {$[3.9,5.8]$} & \\
\hline Do not know & 39.0 & $\begin{array}{l}{[35.3,} \\
42.7]\end{array}$ & 24.0 & $\begin{array}{l}{[22.0} \\
26.1]\end{array}$ & \\
\hline $\begin{array}{l}\text { Access to mental health care since HMP enrollment } \\
\text { Improved }\end{array}$ & 17.4 & 17.4 & 32.2 & {$[30.0$} & $<.001$ \\
\hline Same & 25.8 & 25.8 & 22.1 & $\begin{array}{l}34.4] \\
{[20.2} \\
24.1]\end{array}$ & \\
\hline Worse & 0.4 & 0.4 & 3.4 & {$[2.7,4.4]$} & \\
\hline Do not know & 56.3 & 56.3 & 42.3 & $\begin{array}{l}{[40.1,} \\
44.6]\end{array}$ & \\
\hline Had regular source of medical care in 12 months prior to HMP & 66.6 & $\begin{array}{l}{[63.0} \\
70.0]\end{array}$ & 77.3 & $\begin{array}{l}{[75.3} \\
79.2]\end{array}$ & $<.001$ \\
\hline Had regular source of medical care in 12 months since HMP enrollment & 85.8 & $\begin{array}{l}{[82.6} \\
88.4]\end{array}$ & 95.2 & $\begin{array}{l}{[93.8} \\
96.3]\end{array}$ & $<.001$ \\
\hline $\begin{array}{l}\text { Regular source of care in } 12 \text { months prior to HMP enrollment is doctor's office } \\
\text { or clinic }^{\S}\end{array}$ & 66.3 & - & 64.7 & - & .30 \\
\hline $\begin{array}{l}\text { Regular source of care in } 12 \text { months after HMP enrollment is doctor's office or } \\
\text { clinic }^{\S}\end{array}$ & 88.7 & - & 93.1 & - & .005 \\
\hline
\end{tabular}

Weighted proportions of pre-HMP insurance status and access to care by self-reported chronic conditions

*Chronic conditions are self-reported and include hypertension, mood disorder, asthma, heart disease, chronic obstructive pulmonary disease (COPD), diabetes, and chronic health conditions among those listed by respondents as "other" diagnoses

${ }^{\dagger}$ Pearson's chi-squared test

Fonly asked of those reporting problems paying medical bills in 12 months prior to HMP enrollment

${ }^{\S}$ Only asked of those reporting a regular source of medical care during that time period

Identification of and Treatment for New Diagnoses. Several enrollees who, before enrollment, had been unable to seek care due to lack of coverage were newly diagnosed with chronic physical and mental health conditions.
Without the insurance I'd have never known I had sleep apnea...I probably wouldn't be here now talking to you because my heart stopped beating 97 times per every minute. (male, 47)Some enrollees had been symptom- 
Table 3 Multivariable Logistic Regression Results: Association between Having a Chronic Health Condition and Improved Physical and Mental Health After HMP Enrollment, Among All Respondents

\begin{tabular}{|c|c|c|c|c|}
\hline \multirow[t]{2}{*}{ Independent variables } & \multicolumn{2}{|c|}{$\begin{array}{l}\text { Physical health improved since } \\
\text { HMP enrollment }\end{array}$} & \multicolumn{2}{|c|}{$\begin{array}{l}\text { Mental health improved since } \\
\text { HMP enrollment }\end{array}$} \\
\hline & aOR & $95 \% \mathrm{CI}$ & aOR & $95 \% \mathrm{CI}$ \\
\hline $\begin{array}{l}\text { Any chronic physical or mental health condition } \\
\text { Insurance duration prior to HMP }\end{array}$ & 1.70 & {$[1.40,2.07]^{*}$} & 1.75 & {$[1.43,2.15]^{*}$} \\
\hline Entire year & \multicolumn{3}{|c|}{ Insurance duration prior to HMP } & \\
\hline Part of year & 2.06 & {$[1.51,2.81]^{*}$} & 1.32 & {$[0.96,1.83]$} \\
\hline None of year & 2.34 & {$[1.94,2.82] *$} & 1.66 & {$[1.36,2.02]^{*}$} \\
\hline Current smoker & 0.76 & {$[0.64,0.91]^{*}$} & 0.97 & {$[0.81,1.16]$} \\
\hline \multicolumn{5}{|l|}{ Age } \\
\hline $19-34$ & Ref & & Ref & \\
\hline $35-50$ & 1.24 & {$[1.01,1.52]^{*}$} & 1.05 & {$[0.85,1.30]$} \\
\hline $51-64$ & 1.19 & {$[0.97,1.45]$} & 1.05 & {$[0.85,1.29]$} \\
\hline Female & 0.93 & {$[0.78,1.1]$} & 1.00 & {$[0.84,1.20]$} \\
\hline \multicolumn{5}{|l|}{ Income, $\%$ of federal poverty level } \\
\hline $0-35 \%$ & Ref & & Ref & \\
\hline $36-99 \%$ & 1.07 & {$[0.88,1.30]$} & 0.99 & {$[0.81,1.20]$} \\
\hline$\geq 100 \%$ & 0.93 & {$[0.76,1.14]$} & 0.88 & {$[0.71,1.08]$} \\
\hline \multicolumn{5}{|l|}{ Race } \\
\hline White & Ref & & Ref & \\
\hline Black or African American & 1.22 & {$[0.99,1.50]$} & 1.00 & {$[0.81,1.23]$} \\
\hline Other & 1.02 & {$[0.74,1.40]$} & 0.92 & {$[0.67,1.28]$} \\
\hline More than one & 1.27 & {$[0.81,1.20]$} & 0.95 & {$[0.60,1.52]$} \\
\hline
\end{tabular}

Both logistic regression models adjusted for all independent variables listed in the first column

$* p<.05$

${ }^{*}$ Chronic conditions are self-reported and include hypertension, mood disorder, asthma, heart disease, chronic obstructive pulmonary disease (COPD), diabetes, and chronic health conditions among those listed by respondents as "other" diagnoses

atic but had been undiagnosed until a health care provider was able to identify and address their condition.

Everything fell on top of me at one time. It was like I was buried ... Healthy Michigan came in, and it enabled me to see my doctor and have a physical. My doctor said to me, 'You are clinically depressed. You cannot keep going on like this.' ... She had said, 'You're going on heavy antidepressants here. We are boosting you up.' (female, 62)

\section{Improved Access to Needed Health Care, Medications, and} Supplies for Previously Diagnosed Conditions. Many enrollees with chronic physical and mental health conditions indicated that, prior to HMP enrollment, it was difficult to get needed care for their condition. They described how HMP coverage provided them with access to health care providers, medications, and supplies that helped them better manage their physical and mental health conditions, and improve their functioning and health. For example, HMP coverage helped a man with diabetes afford his medication leading to a dramatic improvement in his blood sugar control.

I had diabetes for 7 years ... . I just ignored it because I couldn't afford the medicine, and how I can get help for it. I got my diabetes under control and I feel a lot better .... I got it [HbA1c] from 10.5 to 6.8. (male, 36)Some enrollees reported that HMP coverage allowed them to stop cutting back from prescribed medication and selfmonitoring regimens.

These [medications] I have to take four times a day, and sometimes [while uninsured] I'd only take them two [times a day]. And the same thing with those test strips. I wouldn't test as often as I should because, again, it's expensive. So now I don't have to worry about that ... I take it like I'm supposed to ... That leads to better health later on. (female, 54)Some enrollees described the benefits of improved access to other health services, including behavioral health and lifestyle programs. This enrollee linked her ability to get behavioral health, physical health, and healthy lifestyle services to improvements in mental health and vice versa.

I know that my mental health is important to my physical health. Everything is connected. So Healthy Michigan has helped me improve in all of those areas. I am mentally stronger because of the behavioral health and because of the physical therapy and because of the Weight Watchers. (female, 62)

Reduced Financial Stress. Many enrollees described how HMP coverage had reduced financial stress related to chronic disease care, allowing them to visit their health care 
Table 4 Multivariable Logistic Regression Results: Associations between Access to Specific Types of Care and Improved Physical and Mental Health After HMP Enrollment, Among Enrollees with Self-reported Chronic Health Conditions

\begin{tabular}{|c|c|c|c|c|}
\hline \multirow[t]{2}{*}{ Independent variables } & \multicolumn{2}{|c|}{$\begin{array}{l}\text { Physical health improved since } \\
\text { HMP enrollment }\end{array}$} & \multicolumn{2}{|c|}{$\begin{array}{l}\text { Mental health improved since } \\
\text { HMP enrollment }\end{array}$} \\
\hline & aOR & $95 \% \mathrm{CI}$ & aOR & $95 \% \mathrm{CI}$ \\
\hline Saw PCP in past 12 months & $1.86^{*}$ & {$[1.20,2.89]$} & 1.02 & {$[0.66,1.59]$} \\
\hline Improved access to prescription medications & $2.10 *$ & {$[1.65,2.68]$} & $1.56^{*}$ & {$[1.21,2.02]$} \\
\hline Improved access to specialty care & $1.63 *$ & {$[1.39,2.05]$} & $1.48 *$ & {$[1.17,1.88]$} \\
\hline Improved access to mental health care ${ }^{\dagger}$ & $1.53 *$ & {$[1.19,1.96]$} & $3.40 *$ & {$[2.67,4.34]$} \\
\hline \multicolumn{5}{|l|}{ Insurance duration prior to HMP } \\
\hline Entire year & Ref & & Ref & \\
\hline Part of year & $1.52 *$ & {$[1.05,2.20]$} & 0.86 & {$[0.59,1.27]$} \\
\hline None of year & $2.15^{*}$ & {$[1.70,2.70]$} & $1.30 *$ & {$[1.02,1.65]$} \\
\hline Current smoker & $0.77 *$ & {$[0.62,0.96]$} & 0.94 & {$[0.76,1.18]$} \\
\hline \multicolumn{5}{|l|}{ Age } \\
\hline $19-34$ & Ref & & Ref & \\
\hline $35-50$ & 1.11 & {$[0.84,1.46]$} & 0.92 & {$[0.69,1.22]$} \\
\hline $51-64$ & 1.05 & {$[0.81,1.37]$} & 1.13 & {$[0.86,1.47]$} \\
\hline Female & $0.78 *$ & {$[0.63,0.97]$} & 0.92 & {$[0.74,1.15]$} \\
\hline \multicolumn{5}{|l|}{ Income, $\%$ of federal poverty level } \\
\hline $0-35 \%$ & Ref & & Ref & \\
\hline $36-99 \%$ & 1.19 & {$[0.93,1.51]$} & 1.02 & {$[0.80,1.30]$} \\
\hline$\geq 100 \%$ & 1.13 & {$[0.88,1.46]$} & 1.03 & {$[0.79,1.34]$} \\
\hline \multicolumn{5}{|l|}{ Race } \\
\hline White & Ref & & Ref & \\
\hline Black or African American & $1.34 *$ & {$[1.02,1.76]$} & 0.92 & {$[0.70,1.20]$} \\
\hline Other & 0.91 & {$[0.58,1.43]$} & 0.82 & {$[0.52,1.28]$} \\
\hline More than one & 1.39 & {$[0.81,2.37]$} & 0.83 & {$[0.43,1.62]$} \\
\hline
\end{tabular}

Both logistic regression models adjusted for all independent variables listed in the first column $* p<.05$

${ }^{*}$ Participants reported that since enrolling in HMP, access to this service has improved (reference group is those who said it got worse, stayed the same, or do not know

${ }^{\dagger}$ (Chronic Conditions Are Self-reported and Include Hypertension, Mood Disorder, Asthma, Heart Disease, Chronic Obstructive Pulmonary Disease (COPD), Diabetes, and Chronic Health Conditions Among Those Listed by Respondents as "Other" Diagnoses)

providers when needed instead of avoiding them for fear of the financial consequences.

You're not afraid to go to the doctor. So you take care of these situations before they get too bad...I'll go to the doctor and say, 'Can we check out my heart?' I'm not afraid anymore because you're not thinking dollars, dollars, dollars. (female, 54)

\section{DISCUSSION}

In this mixed-methods study examining the impact of Medicaid expansion on care of adults with chronic health conditions, we found that $69 \%$ of Healthy Michigan Plan enrollees reported a chronic physical or mental health condition. The prevalence of diabetes, cardiovascular disease, respiratory disease, and mental health conditions in our sample is similar to that previously found among traditional Medicaid enrollees. ${ }^{29}$ Chronic conditions were more common among HMP enrollees than in the general Michigan population of a similar age and sex distribution. The majority of those with chronic health conditions had multiple co-morbid chronic conditions. Over $40 \%$ of those with chronic conditions had a new diagnosis since HMP enrollment.

Most chronically ill enrollees lacked health insurance and access to primary care prior to acquiring HMP coverage. Rates of having any regular source of care, and a doctor's office or clinic as a regular source of care, after enrollment, were higher among HMP enrollees with chronic conditions compared with those without chronic conditions. A 2017 study by Sommers and colleagues ${ }^{13}$ of adults with chronic health conditions in Medicaid expansion states showed increased perceived access to primary care and medications, but worse perceived access to specialty appointments, compared with adults in nonexpansion states. In contrast, 50\% of HMP enrollees with a chronic condition reported improved access to specialty care, and only 5\% reported worse access. Specific HMP features, including the strong emphasis on completing an early PCP visit and use of managed care plans for all enrollees, may have enhanced specialty care access.

There were still gaps in care among those chronic conditions after HMP enrollment. For example, $10 \%$ had not seen a PCP in the last year while enrolled in HMP, and $4 \%$ reported worse access to prescriptions after HMP enrollment. Since improved access to these types of care was associated with improved physical health status among this group, efforts to increase PCP visits and help navigate new prescription coverage among new enrollees should emphasize reaching those with chronic conditions. Expansion programs should be aware that unmet care needs among previously underinsured or uninsured enrollees with chronic conditions may strain the ability to accommodate needed care in initial coverage years. ${ }^{5}$ In other states' studies of Medicaid expansion, improvements 
in access to care and health status were not fully evident until 2-4 years after increased health insurance coverage. ${ }^{13}, 15,30$ Strategies to monitor and overcome any remaining barriers to accessing care after Medicaid enrollment will be key to ensuring that those with chronic health conditions receive the care needed to manage their health conditions and improve their health status.

Most importantly, over half of those with chronic health conditions reported improved physical health, and $43 \%$ reported improved mental health within the first year or two of enrollment in HMP. These findings are consistent with others showing improved self-reported health following pre-ACA state Medicaid expansions, ${ }^{31}$ and more recent similar findings among those with chronic conditions in post-ACA Medicaid expansion states. $^{32}$

HMP enrollees with chronic conditions interviewed in this study confirmed the major findings from the survey, deepening them with enrollees' own words. Major themes included the strong impact of HMP coverage on improved access to care needed to diagnose and manage chronic conditions, reducing financial stress and worry about obtaining needed care, and how HMP led to improved physical and mental health of enrollees. Interviewees described how HMP coverage helped them to obtain prescription medication and supplies, improve medication adherence, and adopt healthy lifestyle changes, all of which helped them to monitor and control their chronic conditions. Among surveyed HMP enrollees with chronic health conditions, improved access to mental health care and specialty care and ability to obtain medications and supplies were associated with improvements in both physical and mental health. In the interviews, many related improvements in physical well-being and improved mental well-being. A recent study comparing population survey results for adults with chronic conditions in states with and without post-ACA Medicaid expansion also found that a large driver of improvements in overall self-rated health was a reduction in poor mental health days. ${ }^{33}$ Newer initiatives that aim to co-locate and integrate behavioral health care with primary care, such as Michigan's Health Homes pilot, ${ }^{34}$ have the potential to enhance access to both types of care for those with chronic conditions.

This study has several limitations. Data on chronic diagnoses, access to care, and health status were obtained through enrollee self-report. However, self-reported health status is a highly significant predictor of mortality risk, ${ }^{35}$ and self-reported access to care has been shown to be accurate. ${ }^{36}$ This cross-sectional study was conducted 1 to 2 years after enrollees obtained Medicaid coverage, and is descriptive, without a comparison or control group. Ongoing longitudinal surveys of this Michigan HMP enrollee cohort will assess trajectories of change in access and health status over time and could assess whether distinctive features of HMP led to some of the improvements seen. Finally, this study was conducted in one Midwestern state. However, a growing number of Medicaid expansion states, and those considering expansion, have features similar to those of HMP, such as a strong emphasis on completing an early PCP visit, incentivizing healthy behaviors, and use of managed care plans for most enrollees.

In conclusion, enrollees with expanded Medicaid coverage reported detection of previously undiagnosed chronic conditions. Among those with chronic conditions, they also noted improved ability to meet medical needs that, if left untreated, could lead to costly complications and disability. Reports of improved health care access were significantly associated with perceived improvements in both physical and mental health in this vulnerable group.

Acknowledgments: The University of Michigan Institute for Healthcare Policy and Innovation (IHPI) is conducting an evaluation of the Healthy Michigan Plan (HMP), as required by the Centers for Medicare \& Medicaid Services (CMS), under contract with the Michigan Department of Health and Human Services (MDHHS).

This study was conducted while Dr. Rosland was a faculty member with the University of Michigan Institute for Healthcare Policy and Innovation.

The authors would like to acknowledge the valuable insights provided by Tammy Chang, Adrianne Haggins, Zachary Rowe from Friends of Parkside and the members of the Healthy Michigan Voices Steering Committee: Karen Calhoun, Michigan Institute for Clinical and Health Research and City Connect Detroit; Adnan Hammad, Global Health Research, Management and Solutions; Lynnette LaHahnn, AuSable Valley Community Mental Health Authority; Charo Ledón, Acción Buenos Vecinos; Raymond Neff, Spectrum Health; Jennifer Raymond, Mid Michigan Community Action; George Sedlacek, Marquette County YMCA; and Ashley Tuomi, American Indian Health and Family Services.

Corresponding Author: Ann-Marie Rosland, MD, MS; Department of Medicine University of Pittsburgh School of Medicine, Pittsburgh, PA, USA (e-mail: roslandam@pitt.edu).

Funding Information This study was funded by MDHHS and CMS but does not represent the official views of either agency. Support was also provided by the Department of Veterans Affairs, Veterans Health Administration, Health Services Research and Development Service. Dr. Kullgren is a VA HSR\&D Career Development awardee.

\section{Compliance with Ethical Standards:}

Conflict of Interest: Dr. Kullgren has received consulting fees from See Change Health and Health Mine, and a speaking honorarium from AbilTo, Inc. All remaining authors declare that they do not have a conflict of interest.

Disclaimer: The views expressed in this article are those of the authors and do not necessarily reflect the position or policy of the Department of Veterans Affairs or the United States government.

\section{REFERENCES}

1. Benjamin RM. Multiple Chronic Conditions: A Public Health Challenge. Public Health Rep. 2010;125(5):626-627.

2. Dieleman JL, Baral R, Birger M, et al. US Spending on Personal Health Care and Public Health, 1996-2013. JAMA. 2016;316(24):2627-2646.

3. Ward BW, Schiller JS, Goodman RA. Multiple chronic conditions among US adults: a 2012 update. Prev Chronic Dis. 2014;11:E62.

4. Shaw KM, Theis KA, Self-Brown S, Roblin DW, Barker L. Chronic Disease Disparities by County Economic Status and Metropolitan Classification, Behavioral Risk Factor Surveillance System, 2013. Prev Chronic Dis. 2016; 13 .

5. Christopher AS, McCormick D, Woolhandler S, Himmelstein DU, Bor DH, Wilper AP. Access to Care and Chronic Disease Outcomes Among 
Medicaid-Insured Persons Versus the Uninsured. Am J Public Health. 2015; 106(1):63-69.

6. Woolhandler S, Himmelstein DU. The Relationship of Health Insurance and Mortality: Is Lack of Insurance Deadly? Ann Intern Med. 2017;167(6):424.

7. McWilliams JM. Health Consequences of Uninsurance among Adults in the United States: Recent Evidence and Implications. Milbank Q. 2009;87(2):443-494.

8. Levy H, Meltzer D. The Impact of Health Insurance on Health. Annu Rev Public Health. 2008;29(1):399-409.

9. Wilper AP, Woolhandler S, Lasser KE, McCormick D, Bor DH, Himmelstein DU. Hypertension, Diabetes, And Elevated Cholesterol Among Insured And Uninsured U.S. Adults. Health Aff 2009;28(6):w1151-w1159.

10. Egan BM, Li J, Small J, Nietert PJ, Sinopoli A. The Growing Gap in Hypertension Control Between Insured and Uninsured Adults: National Health and Nutrition Examination Survey 1988 to 2010. Hypertension. 2014;64:997-1004.

11. Ayanian JZ. Michigan's Approach to Medicaid Expansion and Reform. N Engl J Med. 2013;369(19):1773-1775.

12. Torres H, Poorman E, Tadepalli U, et al. Coverage and access for Americans with chronic disease under the Affordable Care Act: a quasiexperimental study. Ann Intern Med. 2017;166(7):472-479.

13. Sommers BD, Maylone B, Blendon RJ, Orav EJ, Epstein AM. Threeyear impacts of the Affordable Care Act: improved medical care and health among low-income adults. Health Aff. 2017;36(6):1119-1128.

14. Baicker K, Taubman SL, Allen HL, et al. The Oregon Experiment Effects of Medicaid on Clinical Outcomes. N Engl J Med. 2013;368(18): 1713-1722.

15. Miller S, Wherry LR. Health and Access to Care during the First 2 Years of the ACA Medicaid Expansions. New Engl J Med. 2017;376(10):947956.

16. Fertig AR, Carlin CS, Ode S, Long SK. Evidence of Pent-Up Demand for Care After Medicaid Expansion. Med Care Res Rev. 2018;75(4):516-524

17. Kaiser Family Foundation. The Coverage Gap: Uninsured Poor Adults in States That Do Not Expand Medicaid. 2017. Available at: https://www. kff.org/uninsured/issue-brief/the-coverage-gap-uninsured-poor-adultsin-states-that-do-not-expand-medicaid/. Accessed 23 Feb 2018.

18. Decker SL, Kostova D, Kenney GM, Long SK. Health Status, Risk Factors, and Medical Conditions Among Persons Enrolled in Medicaid vs Uninsured Low-Income Adults Potentially Eligible for Medicaid Under the Affordable Care Act. JAMA. 2013;309(24):2579-2586.

19. Bodenheimer T, Wagner EH, Grumbach $\mathbf{K}$. Improving primary care for patients with chronic illness. JAMA. 2002;288(14):1775-1779.

20. American Association for Public Opinion Research. Final Disposition of Case Codes and Outcome Rates for Surveys. 2016.

21. U.S. Department of Health and Human Services, Centers for Disease Control and Prevention. National Health Interview Survey (NHIS). Hyattsville
22. Nelson DE, Holtzman D, Bolen J, Stanwyck CA, Mack KA. Reliability and validity of measures from the behavioral risk factor surveillance system (BRFSS). Soz Praventivmed. 2001;46 Suppl 1:S3-42.

23. U.S. Census Bureau. American Community Survey (ACS). Suitland, MD

24. Agency for Healthcare Research and Quality. Consumer Assessment of Healthcare Providers and Systems (CAHPS). Rockville, MD

25. Inter-university Consortium for Political and Social Research. Center for Studying Health System Change. Health Tracking Household Survey (HTHS). Ann Arbor

26. Center for Studying Health System Change. Health Tracking Household Survey (HTHS). National Health and Nutrition Examination Survey (NHANES). Ann Arbor: Inter-university Consortium for Political and Social Research: Centers for Disease Control and Prevention (CDC)

27. Patton MQ. Qualitative Research \& Evaluation Methods: Integrating Theory and Practice, 4th edn. Sage Publications.

28. Corbin J, Strauss A. Basics of Qualitative Research Techniques and Procedures for Developing Grounded Theory. 4th ed. Sage Publications; 2015.

29. Kaiser Family Foundation. The Role of Medicaid for Adults with Chronic Illnesses. 2012. Available at: https://www.kff.org/health-reform/factsheet/the-role-of-medicaid-for-adults-with/ . Accessed 23 Feb 2018.

30. van der Wees PJ, Zaslavsky AM, Ayanian JZ. Improvements in Health Status after Massachusetts Health Care Reform. Milbank Q. 2013;91(4):663-689.

31. Sommers BD, Baicker K, Epstein AM. Mortality and Access to Care among Adults after State Medicaid Expansions. New Engl J Med. 2012;367(11): 1025-1034.

32. Sommers BD, Blendon RJ, Orav EJ, Epstein AM. Changes in Utilization and Health Among Low-Income Adults After Medicaid Expansion or Expanded Private Insurance. JAMA Intern Med. 2016;176(10):1501-1509.

33. Winkelman TNA, Chang Vw. Medicaid Expansion, Mental Health, and Access to Care among Childless Adults with and without Chronic Conditions. J Gen Intern Med. 2018;33(3):376-383.

34. Michigan Department of Health \& Human Services. MI Care Team Primary Care Health Homes Program. Available at: https://www. michigan.gov/mdhhs/0,5885,7-339-71547_4860_75161\%2D\%2D-,00. html . Accessed 7 July 2018.

35. Idler EL, Benyamini Y. Self-rated health and mortality: a review of twenty-seven community studies. J Health Soc Behav. 1997;38(1):21-37.

36. Prentice JC, Davies ML, Pizer SD. Which outpatient wait-time measures are related to patient satisfaction? Am J Med Qual. 2014;29(3):227-235.

Publisher's Note Springer Nature remains neutral with regard to jurisdictional claims in published maps and institutional affiliations. 